\title{
Stress-dose hydrocortisone reduces critical illness-related corticosteroid insufficiency associated with severe traumatic brain injury in rats
}

Xin Chen ${ }^{1,2,3,4^{*}+}$, Zilong Zhao ${ }^{1,2,3,4 \dagger}$, Yan Chai ${ }^{1,2,3,4+}$, Lanlan Luo ${ }^{5}$, Rongcai Jiang ${ }^{1,2,3,4}$, Jingfei Dong ${ }^{6}$ and Jianning Zhang 1,2,3,4*

\begin{abstract}
Introduction: The spectrum of critical illness-related corticosteroid insufficiency (CIRCI) in severe traumatic brain injury (TBI) is not fully defined and no effective treatments for TBI-induced CIRCl are available to date. Despite growing interest in the use of stress-dose hydrocortisone as a potential therapy for $\mathrm{CIRCl}$, there remains a paucity of data regarding its benefits following severe TBI. This study was designed to investigate the effects of stress-dose hydrocortisone on $\mathrm{CIRCl}$ development and neurological outcomes in a rat model of severe traumatic brain injury.

Methods: Rats were subjected to lateral fluid percussion injury of 3.2-3.5 atmosphere. These rats were then treated with either a stress-dose hydrocortisone ( $\mathrm{HC}, 3 \mathrm{mg} / \mathrm{kg} / \mathrm{d}$ for 5 days, $1.5 \mathrm{mg} / \mathrm{kg}$ on day 6 , and $0.75 \mathrm{mg}$ on day 7 ), a low-dose methylprednisolone (MP, $1 \mathrm{mg} / \mathrm{kg} / \mathrm{d}$ for 5 days, $0.5 \mathrm{mg} / \mathrm{kg}$ on day 6 , and $0.25 \mathrm{mg}$ on day 7 ) or control saline solution intraperitoneally daily for 7 days after injury.
\end{abstract}

Results: We investigated the effects of stress-dose $\mathrm{HC}$ on the mortality, $\mathrm{CIRCl}$ occurrence, and neurological deficits using an electrical stimulation test to assess corticosteroid response and modified neurological severity score (mNSS). We also studied pathological changes in the hypothalamus, especially in the paraventricular nuclei (PVN), after stress-dose HC or a low dose of MP was administered, including apoptosis detected by a TUNEL assay, blood-brain barrier (BBB) permeability assessed by brain water content and Evans Blue extravasation into the cerebral parenchyma, and BBB integrity evaluated by CD31 and claudin-5 expression. We made the following observations. First, $70 \%$ injured rats developed CIRCI, with a peak incidence on post-injury day 7. The TBI-associated $\mathrm{CIRCI}$ was closely correlated with an increased mortality and delayed neurological recovery. Second, post-injury administration of stress-dose $\mathrm{HC}$, but not MP or saline increased corticosteroid response, prevented $\mathrm{CIRCl}$, reduced mortality, and improved neurological function during the first 14 days post injury dosing. Thirdly, these beneficial effects were closely related to improved vascular function by the preservation of tight junctions in surviving endothelial cells, and reduced neural apoptosis in the PVN of hypothalamus.

Conclusions: Our findings indicate that post-injury administration of stress-dose $\mathrm{HC}$, but not MP reduces $\mathrm{CIRCl}$ and improves neurological recovery. These improvements are associated with reducing the damage to the tight junction of vascular endothelial cells and blocking neuronal apoptosis in the PVN of the hypothalamus.

\footnotetext{
*Correspondence: xinchentianjin@me.com; jianningzhang@hotmail.com

${ }^{\dagger}$ Equal contributors

'Department of Neurosurgery, Tianjin Medical University General Hospital, Tianjin 300052, P.R. China

${ }^{2}$ Tianjin Neurological Institute, Tianjin 300052, P.R. China

Full list of author information is available at the end of the article
} 


\section{Introduction}

Traumatic brain injury (TBI) remains a leading cause of death and disability among adolescent males and young adults in China, with an estimated annual cost of $\$ 20$ billion for medical expenses. Approximately 1 million TBI cases are reported each year in emergency rooms throughout China, resulting in 100,000 deaths annually [1].

Critical illness-related corticosteroid insufficiency (CIRCI), defined by the American College of Critical Care Medicine, is used to describe dysfunctions of the hypothalamicpituitary-adrenal (HPA) axis that occurs during critical illness [2]. It is characterized by an exaggerated and protracted pro-inflammatory response and corticosteroid resistance, leading to an inadequate corticosteroid response to severe stress [3]. The incidence of CIRCI varies considerably (up to 77\%) in patients with sepsis, shock, acute respiratory distress syndrome (ARDS), and severe pancreatitis [4-8]. Results from recent clinical trials demonstrate that CIRCI is found in 50 to $70 \%$ of trauma patients, with approximately $34 \%$ mortality despite therapy [9]. However, the incidence of CIRCI in severe TBI has not been fully defined [10].

The pathogenesis of CIRCI in the acute phase of TBI has characteristic features that distinctively differ from those found in other severe illness $[11,12]$. We have previously used electrical stimulation tests, which mimic acute stress that activates the HPA axis in the sub-acute phase of TBI, to assess the adrenal insufficiency in a rat model of TBI. Pathological changes in the model rats are similar in pathophysiology to CIRCI in patients as defined by the American College of Critical Care Medicine [13]. Our previous study in rats suggests that CIRCI could develop during the acute phase of TBI and is closely associated with increased mortality [13]. The apoptosis of cells in the adenohypophysis and in the paraventricular nucleus (PVN) of the hypothalamus might be the pathological characteristics of TBI-associated CIRCI. Additional damage to the HPA axis could further aggravate acute CIRCI, leading to a high fatality [13]. Interventions targeting CIRCI have been implemented in such critical illness [14] as septic shock [15], community-acquired pneumonia [16], and stroke [17], but not in severe TBI, largely because the underlying mechanisms for TBIassociated CIRCI remain poorly understood.

Recent clinical evidence suggests that relatively longterm use of stress-dose of hydrocortisone (HC) $(200 \mathrm{mg}$ per day for 7 days), a natural form of steroid hormone in humans, significantly reduces mortality in patients with septic shock and CIRCI without increasing adverse events [15]. More importantly, stress-dose $\mathrm{HC}$ has also been shown to decrease the incidence of hospital-acquired pneumonia and the time on mechanical ventilation in patients with polytrauma and CIRCI. It is particularly efficient for polytrauma patients with TBI [14]. Recent experimental data suggest that $\mathrm{HC}$ could upregulate metal homeostasis regulator MT-1/2 [18] and anti-apoptotic factor PKC $\varepsilon$ to protect the brain [19]. HC has also been demonstrated to maintain the integrity of endothelial cell tight junctions and to stabilize the blood-brain barrier (BBB) as a mode of glucocorticoid action at a molecular level in the human brain vasculature [20]. However, no data on the use of stress-dose $\mathrm{HC}$ to treat CIRCI in severe TBI are available to date. Whether it reduces CIRCI and improves prognosis after severe TBI remains unknown.

Accordingly, we hypothesize that stress-dose of hydrocortisone decreases neural apoptosis and restores BBB function in the hypothalamus, thus boosting the acute corticosteroid response and reducing post-traumatic CIRCI and TBI mortality. We tested this hypothesis in a rat model of experimentally controlled TBI.

\section{Materials and methods}

Animal care and experiments were conducted in accordance with the ethical approvals stipulated by the Small Animal Protection Board of Tianjin Medical University.

\section{Animals}

Male Wistar rats weighing 300 to $350 \mathrm{~g}$ at the time of surgery were supplied by Experimental Animal Laboratories of the Academy of Military Medical Sciences (Beijing, China). Rats were housed individually in a temperaturecontrolled $\left(22^{\circ} \mathrm{C}\right)$ and humidity-controlled $(60 \%)$ condition, and maintained on a standard 12-h light/dark cycle (7:00 a.m. to 7:00 p.m) with access to food and water $a d$ libitum. All experimental procedures were performed during the light phase between 10:00 a.m. and 2:00 p.m. at the nadir of the circadian cycle for circulating steroid in rats.

Rats were grouped by treatments into: naïve, injury control, HC normal, low-dose methylprednisolone (MP), and stress-dose HC (Table 1). MP, which is a synthetic glucorticoid drug and has also been shown to reduce apoptosis and BBB permeability [21,22], was tested in this setting as the control. The entire experiment consisted of two parts. In the first part, rats from each treatment group were randomly assigned to be evaluated for corticosteroid response and to determine CIRCI incidence after TBI. In the second part, histological examination was performed on the hypothalamus to evaluate brain edema, BBB integrity and permeability, and cellular apoptosis (Figure 1).

\section{Fluid percussion-induced brain injury}

Fluid percussion-induced brain injury (FPI) is an extensively characterized and broadly used preclinical model of closed head injury [23,24]. Briefly, rats were anesthetized with a single intraperitoneal injection of chloral hydrate $(3.0 \mathrm{ml} / \mathrm{kg})$ and placed in a stereotaxic frame. 
Table 1 Experimental groups

\begin{tabular}{|c|c|c|}
\hline Groups & $\begin{array}{l}\text { Number } \\
\text { of rats }\end{array}$ & Treatments \\
\hline Naïve & 66 & None \\
\hline $\begin{array}{l}\text { Hydrocortisone } \\
\text { normal treatment }\end{array}$ & 96 & Hydrocortisone 0.75 to $3,0 \mathrm{mg} / \mathrm{kg}$ \\
\hline Injury control & 227 & $\begin{array}{l}\text { Anesthesia, surgical procedure, } \\
\text { fluid percussion injury and equal } \\
\text { volume of saline }\end{array}$ \\
\hline $\begin{array}{l}\text { Low-dose } \\
\text { methylprednisolone } \\
\text { treatment }\end{array}$ & 185 & $\begin{array}{l}\text { Anesthesia, surgical procedure, } \\
\text { fluid percussion injury and } 0.25 \\
\text { to } 1.0 \mathrm{mg} / \mathrm{kg} \text { methylprednisolone }\end{array}$ \\
\hline $\begin{array}{l}\text { Stress-dose } \\
\text { hydrocortisone } \\
\text { treatment }\end{array}$ & 120 & $\begin{array}{l}\text { Anesthesia, surgical procedure, } \\
\text { fluid percussion injury and } 0.75 \\
\text { to } 3.0 \mathrm{mg} / \mathrm{kg} \text { hydrocortisone }\end{array}$ \\
\hline
\end{tabular}

Craniotomy $(4.0 \times 4.0 \mathrm{~mm})$ was performed over the right parietal bone, $2.0 \mathrm{~mm}$ lateral from the sagittal suture and $2.5 \mathrm{~mm}$ caudal from the coronal suture with intact dura mater. They were subjected to FPI of 3.2 to 3.5 atmosphere (atm) $24 \mathrm{~h}$ after craniotomy as we have previously described [25].

\section{Neurological assessment}

Neurological functions were assessed at baseline before injury, on post-injury day 1 , day 3 , day 7 , and day 14 using the modified neurological severity score (mNSS) [26]. Assessments in the neuroscore include motor, sensory, reflex, and balance tests. These scores were used 1) to ensure the relative uniformity in injury severity; 2) to compare neurological recovery among rats receiving different treatments. The tests were performed by the same observer who was blinded to the experimental conditions and treatments.

\section{Glucocorticoid administration}

After FPI, rats were on a 7-day regimen of either stressdose $\mathrm{HC}(3 \mathrm{mg} / \mathrm{kg} / \mathrm{d}$ for 5 days, $1.5 \mathrm{mg} / \mathrm{kg}$ on day 6 , and $0.75 \mathrm{mg}$ on day 7) [14] or low-dose MP (1 mg/kg/d for 5 days, $0.5 \mathrm{mg} / \mathrm{kg}$ on day 6 , and $0.25 \mathrm{mg}$ on day 7) [27]. As injury controls, naïve rats were given the same dose of HC. For drug controls rats underwent the same surgical procedures and FPI, but received an equal volume of $0.9 \%$ saline (Table 1, Figure 1).

\section{Assessment of corticosteroid response Electrical stimulation}

Thirty rats from each of the four experimental groups were examined for corticosteroid response by being subjected to electrical stimulation (ES) on four test days: the seventh day before injury, and post-injury day 3, 7, and 14 (Figure 1) as described by Ji et al. [28]. In brief, ear-clip electrodes were placed on both ears of the animal while awake, and were connected to an electrical stimulator (unit J18A1; Quanrikang, Beijing, PR China). An electric current (1s at $90 \mathrm{~mA}$ ) was applied to induce acute stress. On the days of electrical stimulation, blood was collected pre-ES, and at 30 minutes, 90 minutes, and $24 \mathrm{~h}$ post-ES to measure dynamic changes of serum corticosterone (CORT), the most abundant circulating steroid in rats. Blood samples were collected from the orbital sinus under inhaled light anesthesia (enflurane; Abbott, Shanghai, PR China) into a dry centrifuge tube

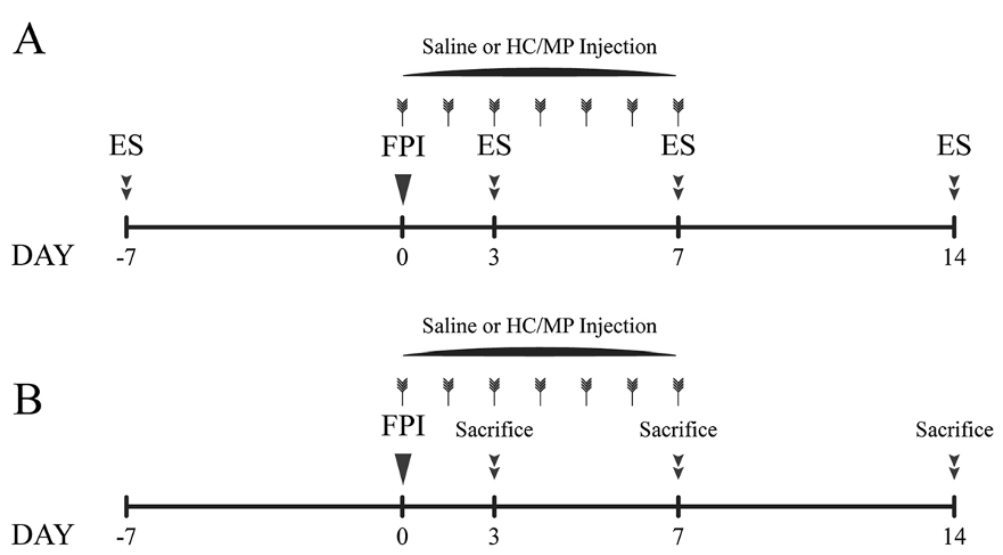

Figure 1 Study design and experimental procedures. (A) Part I: to evaluate the effect of stress-dose hydrocortisone (HC) on corticosteroid responses and incident critical illness-related corticosteroid insufficiency after traumatic brain injury; HC or methylprednisolone (MP), or saline in the case of injury controls, was intraperitoneally (i.p.) injected daily from 0 to 7 days after fluid percussion injury (FPI). Electrical stimulation (ES) was administered to 30 rats randomly assigned from each of the four groups: pre-injury day 7 , and post-injury day 3, day 7 and day 14. (B) Part II: the remaining rats were injected with $\mathrm{HC}$ or MP or saline once a day for 7 days after FPI to evaluate the extent of brain edema, BBB integrity and permeability, and apoptosis in the hypothalamal cells; 22 rats from each of the two groups (naïve and normal $\mathrm{HC}$ ) and 50 from each of the three groups (injury control, low-dose MP, and stress-dose HC) were sacrificed at each time point (post-injury day 3, 7 and 14) to measure brain water content, to detect Evans blue extravasation and expression of CD31 and claudin-5, and to quantify terminal deoxynucleotidyl transferase dUTP nick end labeling-positive cells in the hypothalamus. 
and centrifuged at 3,000 rpm for 8 minutes. Cell-free plasma was collected and stored at $-80^{\circ} \mathrm{C}$ for further CORT assay [29].

\section{Serum corticosterone assay and critical illness-related corticosteroid insufficiency assessment}

Serum levels of CORT were measured using a commercial ELISA kit (Diagnostic Systems Laboratories, Webster, TX, USA), according to the manufacturer's instructions. Corticosteroid responses of injured rats were assessed by a CORT increase index (CII), which is the difference between the post-ES peak value and pre-ES baseline value of CORT, divided by the pre-ES baseline value of CORT. A CII value less than 2.5 was classified as acute CIRCI as described previously [13].

\section{Brain water content}

Edema in the hypothalamus was determined by measuring brain water content (BWC) as previously described [30]. Rats were sacrificed with an overdose of chloral hydrate $(30 \mathrm{ml} / \mathrm{kg}$, i.p.). The brains were promptly removed, and a thick (5-mm) coronal slice was made from the brain (beginning at the bregma). The hypothalamus surrounding the third ventricular area was removed with a 3-mm punch, and immediately weighed (wet weight) and then placed in an incubator at $100^{\circ} \mathrm{C}$ for $24 \mathrm{~h}$. The samples were weighed again to determine the dry weight. The BWC was calculated from:

$$
\begin{aligned}
\text { BWC }(\%)= & {[(\text { Wet Weight-Dry Weight }) / \text { Wet Weight }] } \\
& \times 100 \%
\end{aligned}
$$

\section{Permeability of the blood-brain-barrier}

BBB permeability of the hypothalamus was assessed by measuring the extravasation of Evans blue (EB) dye. EB dye injected intravenously binds instantaneously to albumin and other plasma proteins and serves as a marker for plasma exudation [31]. In brief, EB (2\% in PBS, Sigma) was injected slowly through the jugular vein $(4 \mathrm{ml} / \mathrm{kg})$ and allowed to circulate for $1.5 \mathrm{~h}$. Then, rats were sacrificed and transcardially perfused with $1 \times$ PBS followed by $0.9 \%$ saline. The brain was removed and the hypothalamus around the third ventricle was obtained as described above. The tissue was frozen in $-55^{\circ} \mathrm{C}$ isopentane and freeze dried. Freeze-dried specimens were homogenized in formamide (1:20) and incubated at $60^{\circ} \mathrm{C}$ overnight. The homogenate was centrifuged at $14,000 \mathrm{rpm}$ for 30 minutes to collect supernatant. EB content in the supernatant was determined spectrophotometrically at O.D. $620 \mathrm{~nm}$ (Thermo Scientific, Waltham, MA, USA).

\section{Detection of neuronal apoptosis}

Terminal deoxynucleotidyl transferase dUTP nick end labeling (TUNEL) is a well-defined method for detecting apoptotic DNA fragmentation in a cell [32]. We used the In Situ Cell Death Detection Kit, POD (Roche, Mannheim, Germany) to detect apoptosis in the PVN of the hypothalamus according to the manufacturer's instructions. Rats were sacrificed at designated time points with overdose of chloral hydrate (30 ml/kg, i.p., Figure 1). The brain was removed and fixed in $4 \%$ paraformaldehyde for $24 \mathrm{~h}$. The tissue was then paraffin embedded and processed for immunohistological examination. Two successive brain sections from each rat were stained with H\&E and TUNEL staining, respectively [32]. Briefly, $5-\mu \mathrm{m}$ coronal sections from the brain $(0.7$ to $2.3 \mathrm{~mm}$ posterior to the bregma) were affixed to poly-L-lysine-coated slides and deparaffinized. The sections were rehydrated and treated with protease $\mathrm{K}(20 \mathrm{mg} / \mathrm{ml}$ in $10 \mathrm{mM}$ Tris-HCl; $\mathrm{pH} 7.5$ to 8.0) for 30 minutes at room temperature. They were then incubated at $37^{\circ} \mathrm{C}$ with the TUNEL reaction mixture in a humidified chamber for $3.5 \mathrm{~h}$. The reaction was terminated by washing slides with $0.01 \mathrm{M}$ PBS $(\mathrm{pH}$ 7.4) and then incubated with Converter-POD (anti-fluorescein antibody conjugated with horseradish peroxidase) for $2.5 \mathrm{~h}$ at $37^{\circ} \mathrm{C}$, followed by color development at $20^{\circ} \mathrm{C}$ with 3,3-diaminobenzidine (DAB) substrate. The sections were counterstained with hematoxylin and mounted with neutral balsam.

Apoptotic cells in bilateral areas of the paraventricular nucleus (PVN) in the hypothalamus were counted using light microscopy at 400× (CH20BIMF200; Olympus, Tokyo, Japan). They were quantified by the total number of labeled cells in four sections ( $40 \mu \mathrm{m}$ apart).

\section{Immunohistochemistry and fluorescence intensity quantification}

At designated time points, rats were sacrificed with an overdose of chloral hydrate $(30 \mathrm{ml} / \mathrm{kg}$, i.p.) and immediately perfused through the heart with the phosphate buffer followed by $2 \%$ paraformaldehyde, $10 \mathrm{mM}$ sodium periodate, and $70 \mathrm{mM}$ L-lysine (2\% PLP). The brain was dissected out, post-fixed by immersion in the same fixative for $1 \mathrm{~h}$, and incubated in a solution of $30 \%$ sucrose overnight. It was embedded in optimum cutting temperature (OCT) medium (Sakura, Torrance, CA, USA) on dry ice, and stored at $-80^{\circ} \mathrm{C}$. Coronal sections of $10 \mu \mathrm{m}$ at the hypothalamus level were made on a cryostat at $-20^{\circ} \mathrm{C}$ and imprinted on poly-L-lysine-coated slides. These sections were stained for claudin-5 (a tight-junction marker) and CD31 (an endothelial cell marker).

After air-drying, the sections were fixed with 2\% PLP and rinsed three times in PBS ( $\mathrm{pH}$ 7.4). They were blocked in $1 \%$ normal donkey serum in PBS with $0.1 \%$ Triton X-100 (PBS/Tween (PBST)) at room temperature 
for $1 \mathrm{~h}$, followed by incubation with either a rabbit anticlaudin-5 antibody diluted at 1:500 (Abcam Cambridge, MA, USA) or a mouse anti-CD31 antibody diluted 1:500 (Invitrogen Grand Island, NY, USA) in PBST containing $1 \%$ normal donkey serum at $4{ }^{\circ} \mathrm{C}$ overnight following extensive washing in PBS; the sections were incubated with an Alexa Fluor 488-conjugated goat anti-rabbit IgG antibody at a dilution of 1:1,000 (Invitrogen) and an Alexa Fluor 568-conjugated goat anti-mouse IgG antibody (Invitrogen) for $3 \mathrm{~h}$ at room temperature. Images of immunofluorescence were captured using an Olympus IX81 microscope (Shinjuku-ku, Tokyo, Japan).

The bilateral area of the PVN in the hypothalamus from each section and three sections from each rat were analyzed. Fluorescence intensities, measured using Image J software (from the National Institutes of Health, Bethesda, MD, USA), were averaged for each section, and the three sections were averaged for each rat.

\section{Statistical analyses}

Data were analyzed using SPSS (SPSS Inc., Chicago, IL, USA). Kaplan-Meier survival analysis with the log-rank significance test was used to measure the mortality rates among rats with different treatments. Data on mNSS, CII, apoptotic cell, BWC, EB extravasation and CD31 and claudin-5 expression were analyzed by analysis of variance (ANOVA) followed by post hoc least significant difference (LSD) test or the Dunnett T3 test, whereas acute CIRCI data were analyzed by the Chi-square test. The Pearson Chi-square test was performed to assess the strength of the relationship between the incidence of acute CIRCI and mortality. A $P$-value $<0.05$ was considered statistically significant.

\section{Results}

\section{Baseline characteristics}

A total of 694 Wistar rats were studied. Among them, 532 were subjected to severe FPI of 3.2 to $3.5 \mathrm{~atm}$, which results in severe TBI. The rest were naïve rats and rats that received $\mathrm{HC}$ without surgery and FPI (Table 1). At an injury level of 3.2 to 3.5 atm, rats lapsed into unconsciousness with apnea, regaining spontaneous breathing within 140 to $160 \mathrm{~s}$. Consciousness returned in approximately 280 to $340 \mathrm{~s}$. Severe disturbances in motor function and balance were observed after injury. The motor dysfunction recovered gradually within 7 days, whereas balance improved more slowly.

\section{Stress-dose hydrocortisone reduced traumatic brain injury-associated mortality}

In the first part of the study (Figure 1), 55 rats did not survive after injury and HC or MP treatment (Table 2 and Figure 2). The mortality rate of rats receiving stressdose $\mathrm{HC}(43.3 \%)$ was significantly lower than those of
Table 2 Mortality of experimental groups

\begin{tabular}{|c|c|c|c|}
\hline \multirow[t]{2}{*}{ Groups } & \multicolumn{2}{|c|}{ Outcome } & \multirow{2}{*}{$\begin{array}{c}\text { Total } \\
\text { (number) }\end{array}$} \\
\hline & $\begin{array}{l}\text { Death } \\
\text { (number) }\end{array}$ & $\begin{array}{l}\text { Survival } \\
\text { (number) }\end{array}$ & \\
\hline Hydrocortisone normal treatment & 0 & 30 & 30 \\
\hline Injury control & 22 & 8 & 30 \\
\hline $\begin{array}{l}\text { Low-dose methylprednisolone } \\
\text { treatment }\end{array}$ & 20 & 10 & 30 \\
\hline $\begin{array}{l}\text { Stress-dose methylprednisolone } \\
\text { treatment }\end{array}$ & 13 & 17 & 30 \\
\hline Total & 55 & 65 & 120 \\
\hline
\end{tabular}

rats receiving low-dose MP treatment (66.7\%) and was lower than in the injury control (73.3\%) (Figure 2).

\section{Stress-dose hydrocortisone improved neurological outcomes}

We compared mortality among rats from the four experimental groups during a 14-day follow-up period and found no difference in mNSS $24 \mathrm{~h}$ after FPI (Figure 3). This indicates that the injury was comparable among rats in all experimental groups. FPI at 3.2 to 3.5 atm over the cortex of the right hemisphere led to neurological deficits measured by mNSS (Figure 3 ). On postinjury day 1 , injured rats presented with high scores on motor, sensory and beam balance tests, as well as absent reflexes and abnormal movements. The recovery of neurological functions began on day 3 after injury and lasted to post-injury day 14, when rats suffered from residual neurological deficiencies, presenting with high scores on sensory and beam balance tests. The mNSS scores for the stress-dose $\mathrm{HC}$ treatment were significantly improved on day 7 (mean $6.5 \pm$ SD 1.4; $P<0.05$ ) and day $14(4.2 \pm 1.6 ; P<0.05)$ as compared to those for low-dose MP treatment group and injury control group

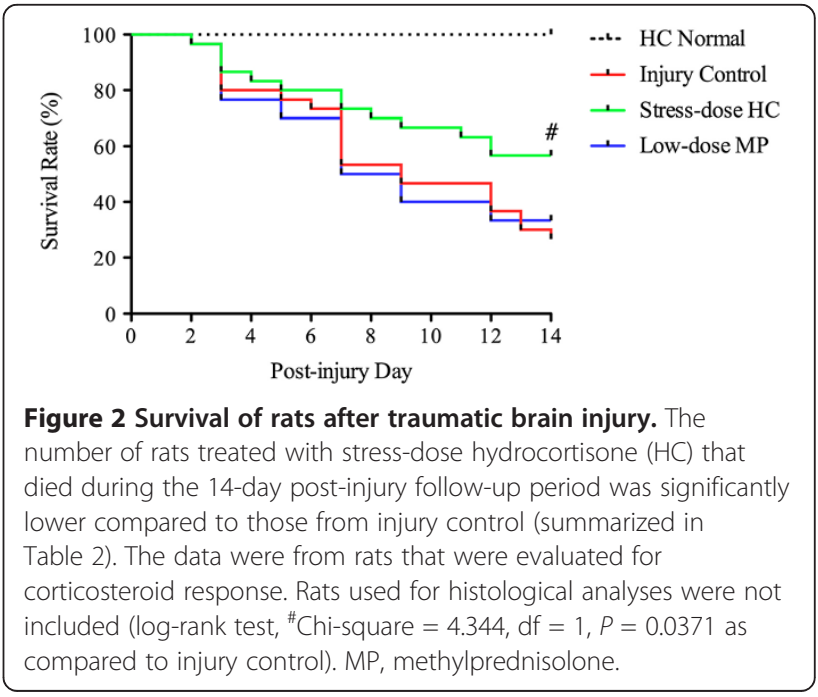




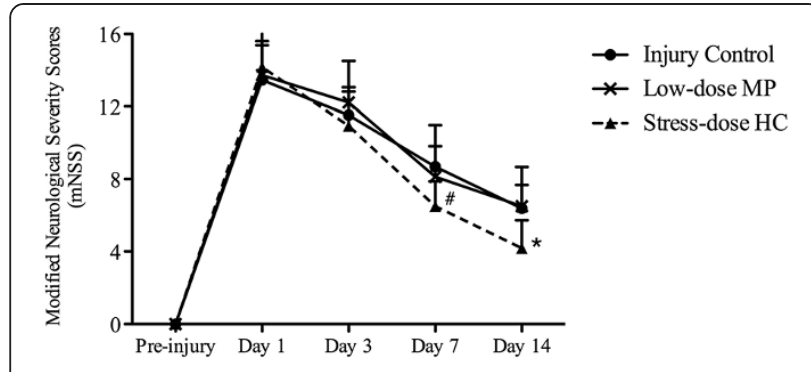

Figure 3 Effects of stress-dose hydrocortisone on neurological outcomes. Injured rats treated with stress-dose hydrocortisone (HC) had significantly lower mNSS scores at day 7 and day 14 after traumatic brain injury when compared with the injury control group. Data are presented as means \pm SD. Analysis of variance: $F_{(2,50)}=7.208, P=0.002$ for day 7 ; post hoc Dunnett T3 test, ${ }^{\#} P=0.000$ for stress-dose HC treatment versus injury control, $F_{(2,32)}=7.762, P=0.002$ for day 14 ; post hoc least significant difference test, ${ }^{*} P=0.006$ for stress-dose $H C$ treatment versus injury control. Day 1: $n=30$ from each group; day $3: n=23$ from injury control, $n=23$ from low-dose methylprednisolone (MP), $n=26$ from stress-dose HC; day 7: $n=16$ from injury control, $n=15$ from low-dose $M P, n=22$ from stress-dose HC; day $14: n=8$ from injury control, $n=10$ from low-dose MP, $n=17$ from stress-dose $H C$.

$(8.1 \pm 2.9$ and $8.7 \pm 1.1$, respectively on day $7 ; 6.5 \pm 2.2$ and $6.4 \pm 1.3$, respectively on day 14 ) (Figure 3 ).

\section{Stress-dose hydrocortisone increased corticosteroid response and reduced incidence of critical illness-related corticosteroid insufficiency}

TBI can result in acute activation of the HPA-axis and ultimately induce rapid secretion of glucocorticoids, norepinephrine, and inflammatory cytokines in order to strengthen a response to traumatic stress. We measured the concentration of CORT, the most abundant steroid released to the peripheral blood in injured rats, in response to ES. We have previously shown that levels of serum CORT increase rapidly after ES, peaking at 30 minutes, declining gradually and returning to baseline level by $24 \mathrm{~h}$ [13]. In the same study, we also demonstrated that the CII, the ratio of increased CORT to the baseline, is a reliable measure to evaluate the activation of the HPA axis. A CII value less than 2.5 was closely correlated with TBI mortality, and considered indicative of CIRCI as described previously [13].

CII, which was comparable among rats in different groups before injury, began to decrease on day 3, reached its lowest point on day 7 , and returned to a level slightly below the baseline on day 14 . It was significantly higher on day 7 in injured rats that received stress-dose HC (median 3.89, IQR 2.29 to 7.28) or low-dose MP (median 2.65, IQR 1.23 to 3.84 ) as compared to control rats (median 2.29, IQR 1.11 to 3.78) (Figure 4).

Furthermore, the incidence of CIRCI in FPI rats treated with stress-dose $\mathrm{HC}(27.3 \%)$ was significantly lower than in those treated with saline $(68.8 \%)$ or low-

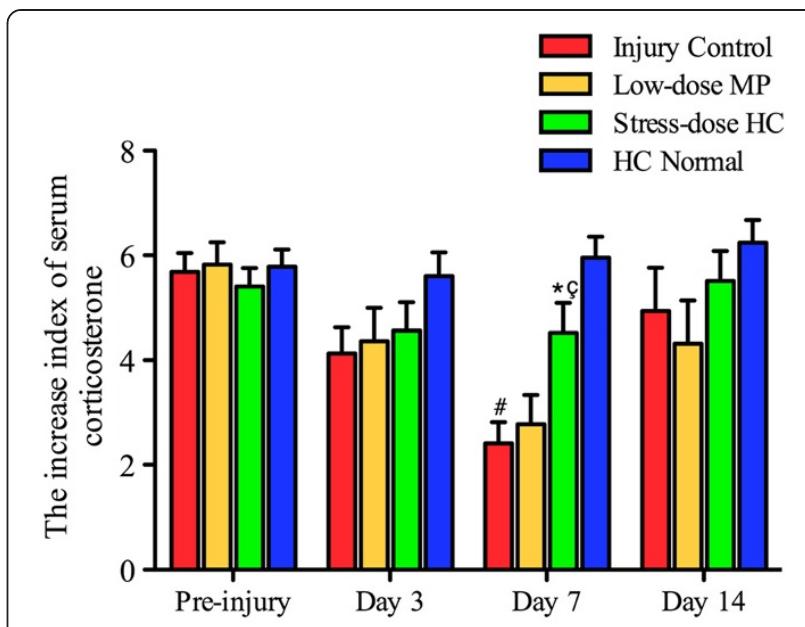

Figure 4 Stress-dose hydrocortisone increases corticosteroid response after traumatic brain injury. Corticosterone increase index (Cll) of rats treated with stress-dose hydrocortisone $(\mathrm{HC})$ was significantly higher than that of those from the injury control group or those treated with low-dose methylprednisolone (MP) on day 7 post-injury. Data are expressed as mean \pm standard error of the mean. $\left(\# P<0.001\right.$ as compared to HC normal treatment; ${ }^{*} P=0.005$ as compared to injury control; ${ }^{\varsigma} P=0.022$ as compared to low-dose MP). Pre-injury: $n=30$ from each group; day $3: n=30$ from HC normal, $n=23$ from injury control, $n=23$ from low-dose MP, $\mathrm{n}=26$ from stress-dose $\mathrm{HC}$; day $7: \mathrm{n}=30$ from $\mathrm{HC}$ normal, $\mathrm{n}=16$ from injury control, $n=15$ from low-dose MP, $n=22$ from stressdose HC; day $14: \mathrm{n}=30$ from HC normal, $n=8$ from injury control, $n=10$ from low-dose MP, $n=17$ from stress-dose HC.

dose MP (46.6\%) on post-injury day 7 (Figure 5). The reduction of CIRCI was paralleled with a decrease in TBI mortality $($ Pearson Chi-Square $=20.972, P<0.001$ ) (Figures 2 and 5).

Together, these results suggest that (1) TBI resulted in acute CIRCI with a peak incidence on day 7 after injury; (2) stress-dose $\mathrm{HC}$ did not induce CIRCI in rats without injury; (3) stress-dose $\mathrm{HC}$ reduced the incidence of CIRCI after TBI, which may be a key factor for reducing mortality in rats with severe TBI.

\section{Stress-dose hydrocortisone reduced apoptosis in the paraventricular nucleii of the hypothalamus}

TBI-induced corticosteroid response is initiated by signals from the PVN of the hypothalamus. Previous studies have shown that FPI causes neural apoptosis in this region [13]. Reducing the viability of cells in this region can negatively impact on the activation of the HPA axis. We therefore examined if the improvements on $\mathrm{CII}$ and CIRCI in rats treated with stress-dose $\mathrm{HC}$ is associated with reduced apoptosis in PVN cells.

H\&E staining showed that cells in the PVN of the hypothalamus became swollen and vacuolated after FPI. Over time, neurons shrank and became eosinophilic with pyknosistic nuclei. Three days after FPI, neuronal 


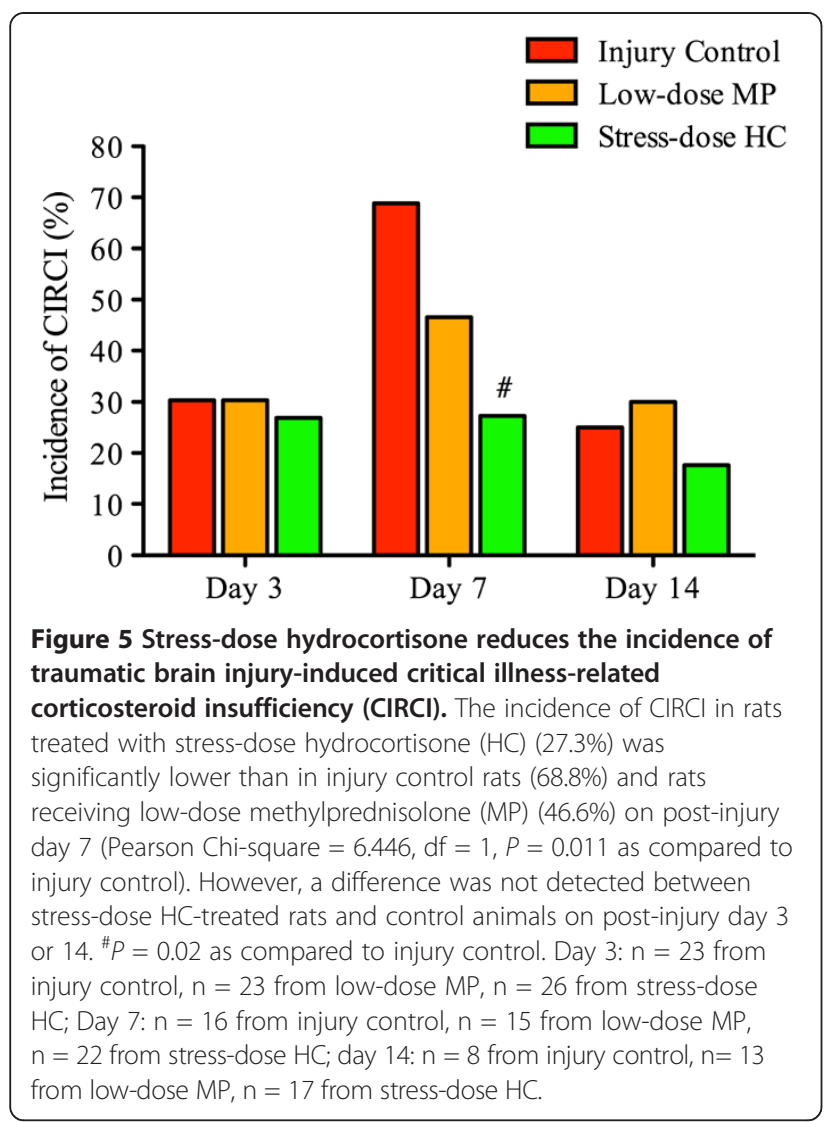

degeneration was observed, and both karyorrhexis and karyolysis were found in many PVN neurons and were most abundant on day 7 after injury. Figure 6 shows that TUNEL-positive cells significantly increased in the hypothalamus PVN of injured rats compared to non-injured rats. The numbers of TUNEL-labeled cells peaked 7 days after injury, when the incidence of CIRCI was also highest (Figures 5 and 6). Moreover, the number of TUNEL-positive cells was significantly reduced in rats receiving stress-dose $\mathrm{HC}$ (median 47.5, IQR 34.75 to 73.25) compared to injury control rats on post-injury day 7 (median 81.0, IQR 69.25 to 90.25).

\section{Stress-dose hydrocortisone reduced traumatic brain injury-associated vascular dysfunction}

TBI compromises cerebral auto-regulation and breaks down the BBB, allowing blood cells and plasma infiltrate into the brain [33]. Several studies have shown that FPI causes an increase in vascular permeability, primarily in the ipsilateral hemisphere $[30,34,35]$. Figure $7 \mathrm{C}$ shows that TBI increased EB extravasation in the hypothalamus of injured rats as compared with control animals, and the post-injury administration of stress-dose $\mathrm{HC}$ significantly reduced this extravasation 3 days after injury. The same effects were also observed after low-dose MP administration, but to a lesser extent. No significant

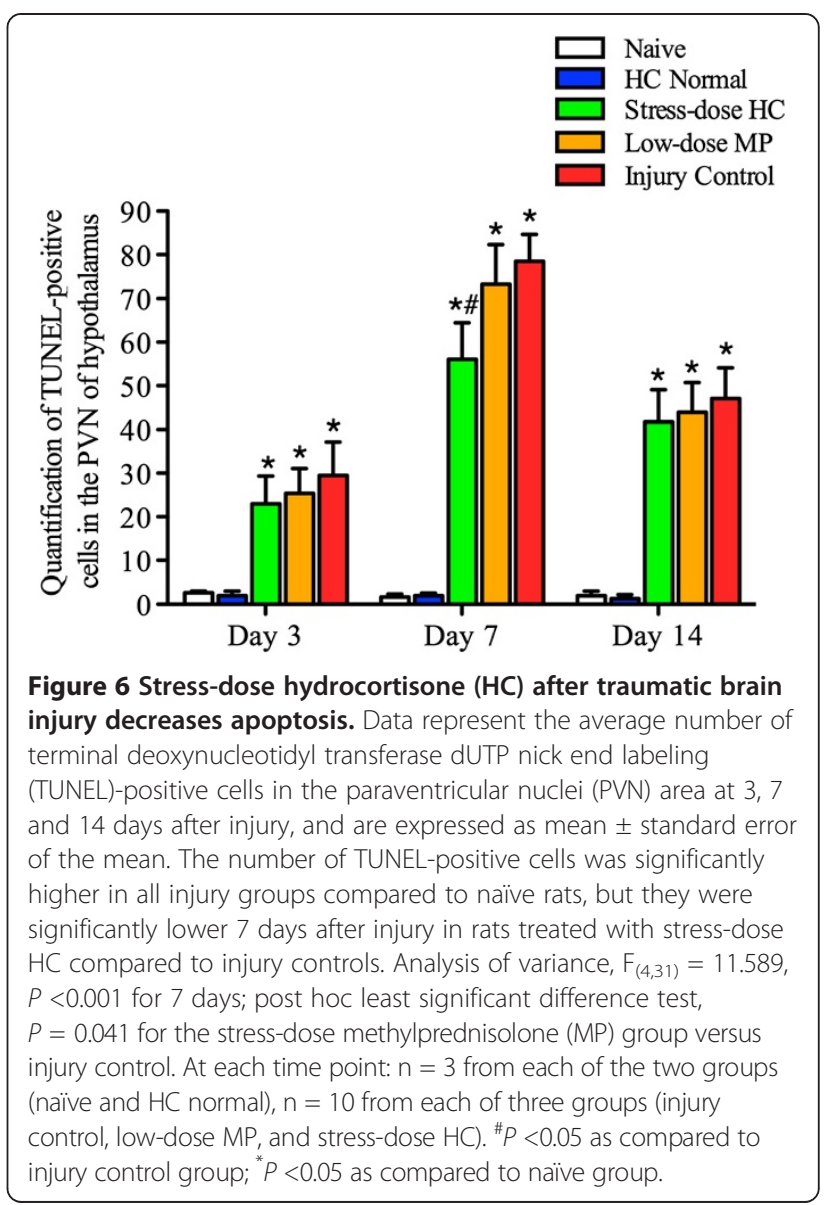

differences were observed among groups on either day 7 or 14 after injury. Figure 7D shows that water content in the hypothalamus increased significantly on post-injury day 3 and returned to pre-injury level on post-injury day 7. Both stress-dose $\mathrm{HC}$ and low-dose MP significantly reduced the water content 3 days after injury, but at different levels.

\section{Stress-dose hydrocortisone reduced traumatic brain injury-induced loss of endothelial cell and tight junction protein}

Figure $8 \mathrm{~A}$ and $\mathrm{B}$ are representative immunofluorescence images of blood vessels labeled with CD31 and claudin- 5 in the PVN of the ipsilateral hypothalamus. CD31, a receptor on endothelial junctions, was used to define the location of the blood vessel. Consistent with it being expressed at tight junctions of endothelium, claudin-5 is localized to the plasma membrane as a continuous striplike staining pattern along the vasculature. Figure $8 \mathrm{C}$ shows that brain injury significantly decreased the immunoreactivity of CD31 and claudin-5 after injury. They were lowest on post-injury day 3 , when significant BBB leakage was also detected by EB extravasation. Importantly, the immunoreactivity was significantly increased 


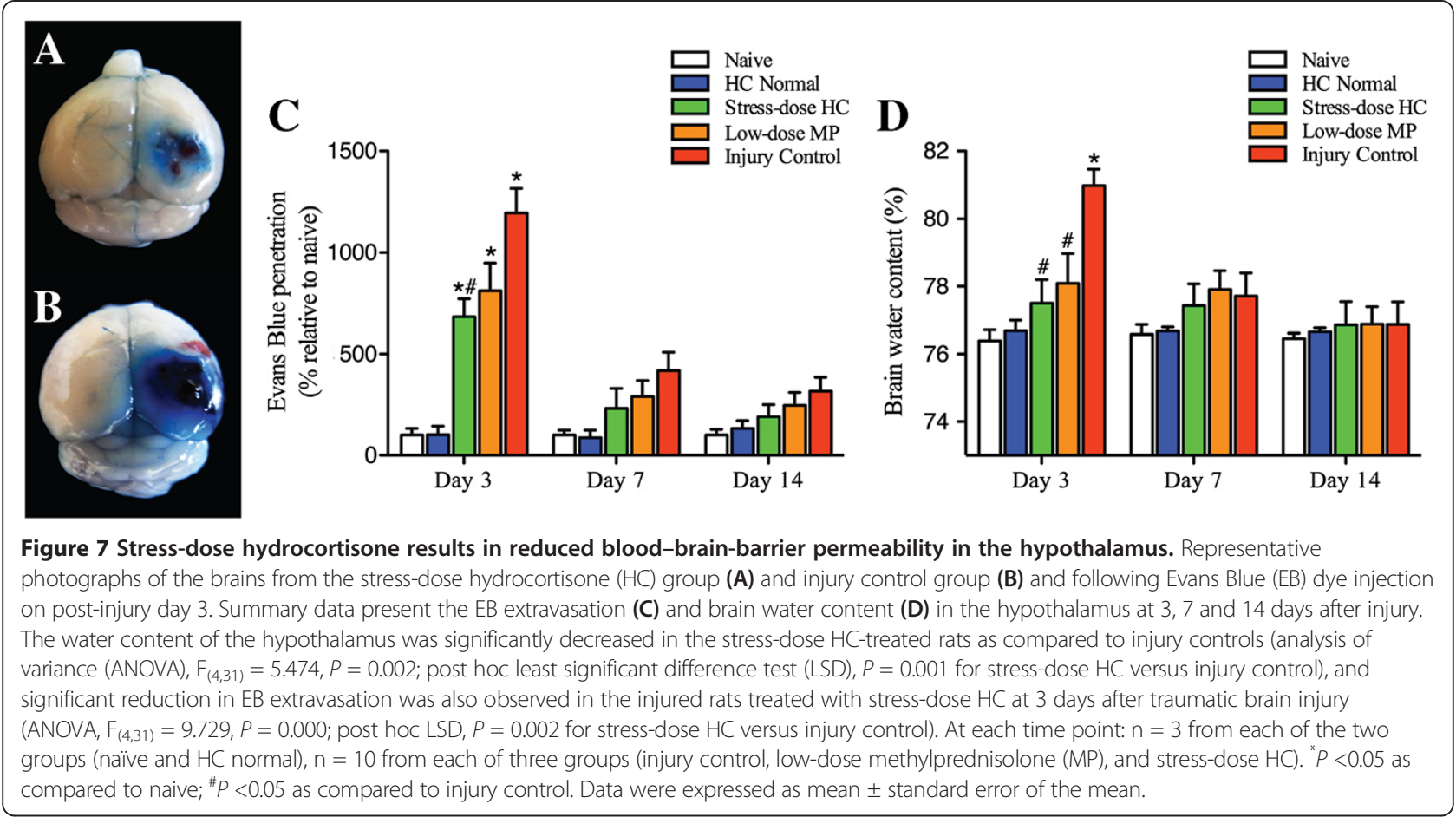

in the brain from rats treated with stress-dose $\mathrm{HC}$, when overt improvement of $\mathrm{BBB}$ permeability was also observed. Stress-dose HC appears to protect the levels of claudin-5 expression, suggesting that the vascular integrity may have been preserved. Compared with a moderate increase in CD31 expression, increase in claudin-5 expression in the hypothalamus was more intensely detected by immunohistochemical staining and western blot, suggesting the preservation of tight junctions (Figure $8 \mathrm{C}$ and $\mathrm{D}$ ).

\section{Discussion}

In the present study, we examined changes in the corticosteroid response of rats to experimentally controlled severe FPI to the brain and correlated such changes to BBB dysfunction and neuronal apoptosis in the PVN of the hypothalamus. We compared these changes between rats receiving a 7-day treatment of stress-dose $\mathrm{HC}$ and those receiving low-dose MP. Our findings can be summarized as follows. First, 30 to $70 \%$ of injured rats developed CIRCI, peaking on post-injury day 7 . The TBI-associated CIRCI was closely correlated with increased mortality and delayed neurological recovery. Second, post-injury treatment of rats with stress-dose $\mathrm{HC}$ reduced TBI-associated mortality and improved the recovery of neurological functions. Moreover, it increased corticosteroid response and prevented the development of CIRCI, which closely correlates with mortality. Third, stress-dose $\mathrm{HC}$ reduced neural apoptosis, preserved endothelial tight junction, and reduced BBB permeability in the PVN of the hypothalamus, starting on post-injury day 3. However these effects of stress-dose HC have not been observed in rats treated with low-dose MP.

There is increasing evidence to suggest that the dysfunction of the HPA axis occurs in a variety of critically ill patients, and is referred to as CIRCI $[14,36]$. Research and clinical interest has been increasingly focused on understanding the role of CIRCI in the pathological course of severe TBI. A recent retrospective clinical analysis suggests that CIRCI could develop in up to 50 to $70 \%$ of trauma patients with a mortality of $34 \%$ despite pharmacotherapy. To the best of our knowledge, no data on the spectrum of CIRCI in severe TBI are available to date. The detection of CIRCI in experimental animals has been difficult because there are no universally accepted diagnostic criteria [37]. We have previously described a set of criteria that can be used to define CIRCI in rats subjected to FPI based on an ES test that mimics acute stress, which activates the HPA axis in the subacute phase of TBI [13]. Using this platform, we found 30 to $70 \%$ of TBI rats developed CIRCI, with a peak incidence on post-injury day 7. The TBI-induced CIRCI was closely correlated with increased mortality and delayed neurological recovery.

Stress-dose $\mathrm{HC}$, equivalent to the maximal endocrine secretion rate during critical illness, has been recommended for CIRCI patients with ARDS [2]. It has been reported to reduce death in these patients without increasing adverse events [38]. Emerging evidence suggests that this treatment could also reduce the occurrence of hospital-acquired 


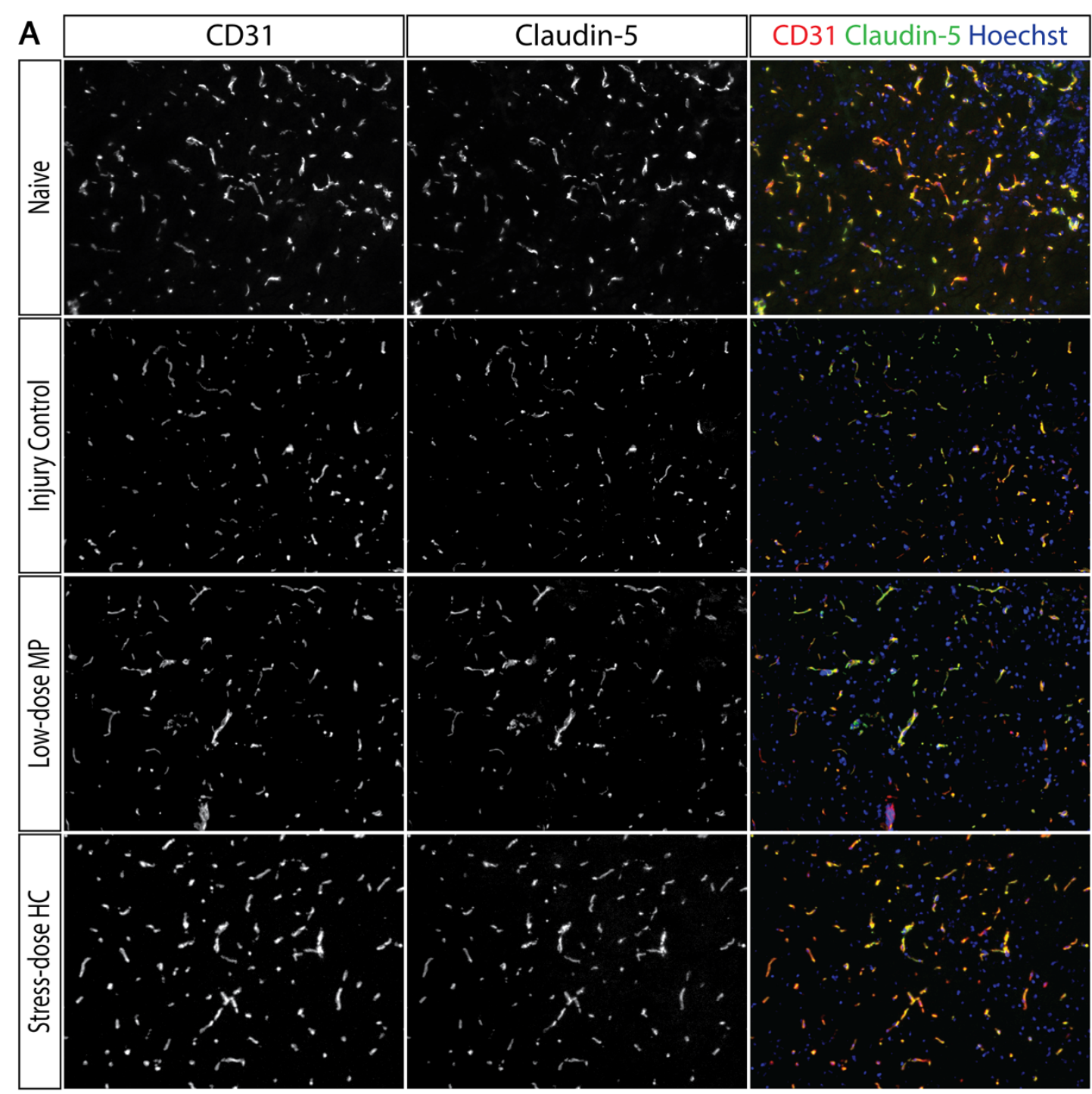

B

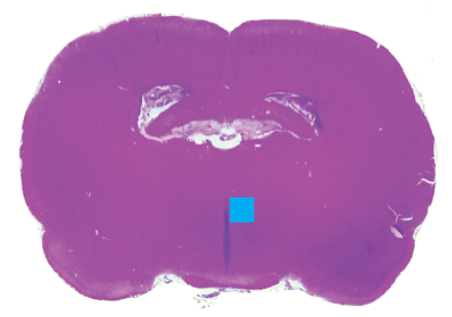

D

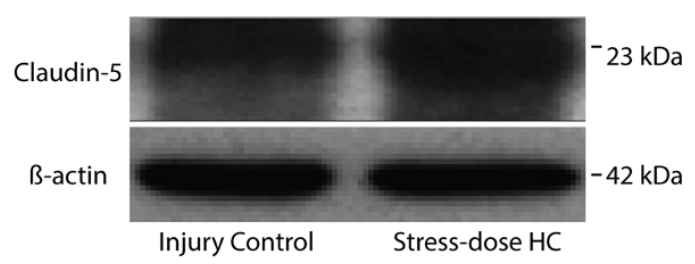

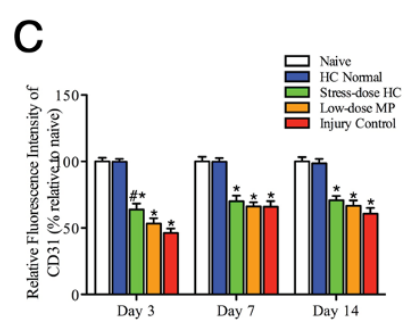

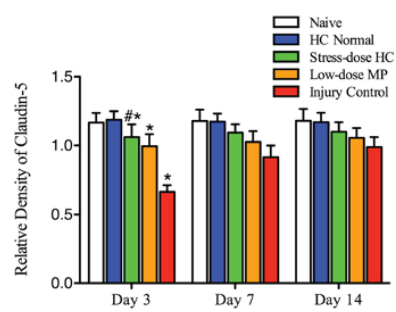

Figure $\mathbf{8}$ (See legend on next page.) 
(See figure on previous page.)

Figure 8 Stress-dose hydrocortisone reduces the loss of CD31 and claudin-5 in the paraventricular nuclei (PVN) of the hypothalamus following trauamatic brain injury (TBI). (A) Representative images of blood vessels in ipsilateral hypothalamus, immunostained for endothelial cell marker CD31, and tight junction protein Claudin-5. Stress-dose hydrocortisone (HC) appears to partially preserve loss of CD31 and claudin-5 caused by $\mathrm{TBI}$, more pronounced with claudin-5. (B) Region of interest for immunoreactivity analysis was the PVN of the bilateral hypothalamus. Blue square indicates where the immunofluorescence pictures (A) were taken. (C) Summary data shows immunoreactivity of CD31 and claudin-5 were lowest on post-injury day 3, when significant BBB leakage was detected by EB extravasation measurement. Importantly, they were significantly increased by the administration of stress-dose HC, when overt improvement of BBB permeability was also observed. Analysis of variance (ANOVA), $F_{(4,45)}=54.625$, $P=0.000$ for CD31 comparison on day 3; post hoc least significant difference (LSD), $P=0.001$ for stress-dose HC versus injury control, $P=0.000$ for injury control versus naïve. $F_{(4,45)}=82.263, P=0.000$ for claudin- 5 comparison; post hoc Dunnett T3, $P=0.000$ for stress-dose HC versus injury control, $P=0.000$ for injury control versus naive. (D) Representative western blot and summary data shows increased claudin-5 expression in the hypothalamus following administration of stress-dose $\mathrm{HC}$ on post-injury day 3 . ANOVA, $F_{(4,31)}=5.716, P=0.001$; post hoc LSD, $P=0.001$ for stress-dose HC versus injury control, $P=0.003$ for injury control versus naive. At each time point: $n=3$ from each of the two groups (naïve and $\mathrm{HC}$ normal), $\mathrm{n}=10$ from each of three groups (injury control, low-dose methylprednisolone (MP), and stress-dose HC). Data are mean \pm standard error of the mean.

pneumonia and the use of mechanical ventilation in patients with polytrauma and CIRCI [14]. Consistent with this, we found that post-injury administration of stressdose $\mathrm{HC}$ increased the corticosteroid response and attenuated CIRCI following severe TBI. The restoration of the HPA axis function is closely associated with improved neurological outcomes and a reduced mortality.

Although the mechanism by which it efficiently reduces CIRCI-associated mortality is not completely known, the potent anti-inflammatory properties of stress-dose $\mathrm{HC}$ might enhance or accelerate the recovery of corticosteroid response to severe TBI. After initial injury, an injured brain is exposed to exaggerated inflammatory response and a large amount of cytokines activate the HPA axis. However, recent studies further suggest that excessive secretion of cytokines might cause CIRCI by suppressing the function of the HPA axis. The serum concentration of pr-inflammatory mediators, such as IL- 6 and TNF- $\alpha$, were shown to be markedly increased in CIRCI associated with septic shock [37] and TBI [39]. TNF- $\alpha$ has been shown to inhibit adrenocorticotrophic hormone (ACTH)-induced production of cortisol by suppressing the steroidogenic expression of P450 enzyme [40]. Stress-dose HC has been shown to efficiently suppress the production and activity of pro-inflammatory cytokines during TBI by inhibiting the nuclear factor (NF)- $\mathrm{B}$ signaling pathway. This is in a sharp contrast to the high-dose glucocorticoid therapy that is reported to increase the risk of death in TBI [25,41-43].

In the present study, we showed that stress-dose $\mathrm{HC}$ reduced neuronal apoptosis in the PVN of the hypothalamus induced by TBI. This observation is consistent with previous studies by several laboratories, including our own $[13,25,44]$. By reducing apoptosis, stress-dose HC could prevent the disruption of corticotropin releasing hormone $(\mathrm{CRH})$ transmission in the HPA axis and reduce $\mathrm{CIRCI}$; both are prevalent in rats with severe TBI.

This anti-apoptotic effect could also explain why stressdose $\mathrm{HC}$ improves vascular integrity as demonstrated by reducing the $\mathrm{TBI}$-associated leakage of $\mathrm{BBB}$. A disruption of BBB will allow the infiltration of circulating cells, plasma molecules, and fluid into the brain to exacerbate injury to the brain by FPI [45-48]. Our histological and immunochemical examinations of injured brain demonstrate that stress-dose $\mathrm{HC}$ increases molecules that are primarily expressed at the tight junctions of the vascular endothelium such as claudin-5. Our findings are consistent with previous reports that $\mathrm{HC}$ can maintain the integrity of tight junctions and thus, stabilize the $\mathrm{BBB}$ [20]. The activation of endogenous antioxidant proteins and inhibition of neuroinflammation restores claudin-5 levels and protects against TBI-induced increase in BBB permeability $[49,50]$.

In contrast, we found low-dose MP neither reduced TBI-induced mortality nor improved the recovery of neurological function, which is the opposite of what we observed for treatment with stress-dose HC. Low-dose $\mathrm{MP}$ was also less effective in reducing apoptosis and improving $\mathrm{BBB}$ permeability in the PVN of the hypothalamus compared to stress-dose $\mathrm{HC}$. One can speculate about the potential causes for this discrapany between the two gluococorticoids. First, $\mathrm{HC}$ has been shown to be four times more able to activate mineralocorticosteroid receptor (MR), but is four fifth less able to activate the glucocorticoid receptor (GR) compared to MP [51]. Recent studies also suggest that the difference in the rates of activation of MR and GR may account for this discrepancy [52]. For example, Chantong et al., show that the balance between activated MR and GR is critical for neuronal excitability, stress responsiveness and behavioral adaptation. GR over-activation could modulate the activity of the excitatory and inhibitory neural inputs to the hypothalamic $\mathrm{CRH}$ neurons, and thus, block the stress-induced HPA activation in these neurons [53]. However, De Kloet et al., suggest limbic MR activation maintains the basal HPA activity and the sensitivity or threshold of the central stress response system [54]. Furthermore, the activation of MR and GR has pro- and anti- apoptosis effects, depending on the type of target cells, including those critical for the integrity of the BBB [55-57]. 
The study is limited in its ability to determine whether the finding 1) can also be observed with female rats and is gender specific; 2) might be associated with change in partial arterial pressure $(\mathrm{Pa}) \mathrm{CO} 2, \mathrm{PaO} 2$ and body temperature, which are key factors in the evolution of brain injuries, or the change in cytokine dosing in the brain or in the blood, which can directly influence hypothalamopituitary functions. Nevertheless, this study suggests that the improvement of BBB integrity and survival of hypothalamic neurons are two key activities that make stress-dose $\mathrm{HC}$ effective in improving neurological functions and reducing mortality in rats subjected to severe TBI.

\section{Conclusions}

In summary, our findings add to the growing body of evidence supporting the use of stress-dose $\mathrm{HC}$ to improve outcomes of severe TBI. Stress-dose HC reduces CIRCI and improves neurological recovery, which is associated with reduction in damage to the tight junctions of vascular endothelial cells and neuronal apoptosis in the PVN of the hypothalamus. Therefore, translating this strategy to a clinical context may have potentially important therapeutic significance.

\section{Key messages}

- The TBI-associated CIRCI is closely correlated with increased mortality and delayed neurological recovery. The peak incidence of CIRCI is on postinjury day 7

- Post-injury treatment with stress-dose HC reduces TBI-associated mortality and improves the recovery of neurological function

- Stress-dose HC treatment increases corticosteroid response and prevents the development of CIRCI, which closely correlates with reduction in mortality

- Stress-dose HC treatment reduces neural apoptosis, preserves endothelial tight junctions, and reduces BBB permeability in the PVN of hypothalamus

- Stress-dose HC can be considered as a potential treatment for TBI-induced CIRCI

\footnotetext{
Abbreviations

ANOVA: Analysis of variance; ARDS: Acute respiratory distress syndrome; Atm: Atmosphere; BBB: Blood-brain-barrier; BWC: Brain water content; Cll: Corticosterone increase index; CIRCI: Critical illness-related corticosteroid insufficiency; CORT: Corticosterone; EB: Evans blue; ELISA: Enzyme-linked immunosorbent assay; ES: Electrical stimulation; FPI: Fluid percussion injury; GR: Glucocorticoid receptor; H\&E: Hematoxylin and eosin; HC: Hydrocortisone; HPA: Hypothalamus-pituitary-adrenal axis; i.p: Intraperitoneally; IL: Interleukin; LSD: Least significant difference; mNSS: Modified neurological severity score; MP: Methylprednisolone; MR: Mineralocorticosteroid receptor; PBS: Phosphatebuffered saline; PBST: Phosphate-buffered saline/Tween; PVN: Paraventricular nuclei; TBI: Traumatic brain injury; TNF-03B1: Tumor necrosis factor;

TUNEL: Terminal deoxynucleotidyl transferase dUTP nick end labeling.
}

\section{Competing interests}

The authors declare that they have no competing interests.

\section{Authors' contributions}

$X C$ and JZ designed the experiment and wrote the manuscript. JD summarized, analyzed the data, and edited the manuscript. XC, ZZ, YC, LL and RJ performed the experiment. All authors read and approved the final manuscript.

\section{Acknowledgements}

This work was supported by grants from the National Natural Science Foundation of China (grant no. 81000533), and the Project of Tianjin Applied Basic and Cutting-edge Technological Research (13JCQNJC10500).

\section{Author details}

${ }^{1}$ Department of Neurosurgery, Tianjin Medical University General Hospital, Tianjin 300052, P.R. China. ${ }^{2}$ Tianjin Neurological Institute, Tianjin 300052, P.R. China. ${ }^{3}$ Key Laboratory of Post-trauma Neuro-repair and Regeneration in Central Nervous System, Ministry of Education, Tianjin 300052, P.R. China. ${ }^{4}$ Tianjin Key Laboratory of Injuries, Variations and Regeneration of Nervous System, Tianjin 300052, P.R. China. ${ }^{5}$ Department of Psychology, Tianjin Huanhu Hospital, Tianjin 300060, P.R. China. ${ }^{6}$ Hematology Division, Department of Medicine, Puget Sound Blood Research Institute (JD), University of Washington, Seattle, WA 98104, USA.

Received: 28 June 2013 Accepted: 17 September 2013

Published: 16 October 2013

\section{References}

1. Zhao YD, Wang W: Neurosurgical trauma in People's Republic of China. World J Surg 2001, 25:1202-1204.

2. Marik PE, Pastores SM, Annane D, Meduri GU, Sprung CL, Arlt W, Keh D, Briegel J, Beishuizen A, Dimopoulou I, Tsagarakis S, Singer M, Chrousos GP, Zaloga G, Bokhari F, Vogeser M: Recommendations for the diagnosis and management of corticosteroid insufficiency in critically ill adult patients: consensus statements from an international task force by the American College of Critical Care Medicine. Crit Care Med 2008, 36:1937-1949.

3. Polito A, Annane D: Adrenocortical cell tolerance to lipopolysaccharide: a new mechanism for critical illness related corticosteroid insufficiency. Crit Care Med 2011, 39:597-598.

4. Marik PE: Critical illness-related corticosteroid insufficiency. Chest 2009, 135:181-193.

5. Meduri GU, Golden E, Freire AX, Taylor E, Zaman M, Carson SJ, Gibson M, Umberger R: Methylprednisolone infusion in early severe ARDS: results of a randomized controlled trial. Chest 2007, 131:954-963.

6. Triantos CK, Marzigie M, Fede G, Michalaki M, Giannakopoulou D, Thomopoulos K, Garcovich M, Maria K, Chronis A, Kyriazopoulou V, Jelastopoulou E, Nikolopoulou V, O'Beirne J, Burroughs AK: Critical illnessrelated corticosteroid insufficiency in patients with cirrhosis and variceal bleeding. Clin Gastroenterol Hepatol 2011, 9:595-601.

7. Peng YS, Wu CS, Chen YC, Lien JM, Tian YC, Fang JT, Yang C, Chu YY, Hung CF, Yang CW, Chen PC, Tsai MH: Critical illness-related corticosteroid insufficiency in patients with severe acute biliary pancreatitis: a prospective cohort study. Crit Care 2009, 13:R123.

8. Jung B, Clavieras N, Nougaret S, Molinari N, Roquilly A, Cisse M, Carr J, Chanques G, Asehnoune K, Jaber S: Effects of etomidate on complications related to intubation and on mortality in septic shock patients treated with hydrocortisone: a propensity score analysis. Crit Care 2012, 16:R224.

9. Walker ML, Owen PS, Sampson C, Marshall J, Pounds T, Henderson VJ: Incidence and outcomes of critical illness-related corticosteroid insufficiency in trauma patients. Am Surg 2011, 77:579-585.

10. Levin $H$, Smith D: Traumatic brain injury: networks and neuropathology. Lancet Neurol 2013, 12:15-16.

11. Schneider HJ, Kreitschmann-Andermahr I, Ghigo E, Stalla GK, Agha A Hypothalamopituitary dysfunction following traumatic brain injury and aneurysmal subarachnoid hemorrhage: a systematic review. JAMA 2007, 298:1429-1438.

12. Arafah BM: Hypothalamic pituitary adrenal function during critical illness: limitations of current assessment methods. J Clin Endocrinol Metab 2006, 91:3725-3745

13. Chen $X$, Zhang $B$, Chai $Y$, Dong B, Lei $P$, Jiang $R$, Zhang J: Methylprednisolone exacerbates acute critical illness-related corticosteroid insufficiency associated with traumatic brain injury in rats. Brain Res 2011, 1382:298-307. 
14. Roquilly A, Mahe PJ, Seguin P, Guitton C, Floch H, Tellier AC, Merson L, Renard B, Malledant Y, Flet L, Sebille V, Volteau C, Masson D, Nguyen JM, Lejus C, Asehnoune K: Hydrocortisone therapy for patients with multiple trauma: the randomized controlled HYPOLYTE study. JAMA 2011, 305:1201-1209.

15. Sprung $C L$, Annane $D$, Keh D, Moreno R, Singer M, Freivogel $K$, Weiss $Y G$ Benbenishty J, Kalenka A, Forst H, et al: Hydrocortisone therapy for patients with septic shock. N Engl J Med 2008, 358:111-124.

16. Annane D, Meduri GU, Marik P: Critical illness-related corticosteroid insufficiency and community-acquired pneumonia: back to the future! Eur Respir J 2008, 31:1150-1152.

17. Miyauchi T, Tsuruta R, Kutsuna S, Nakahara T, Fujita M, Kasaoka S, Maekawa T: Successful treatment with hydrocortisone for heat stroke with critical illness-related corticosteroid insufficiency: transitional changes in serum cytokine and cortisol concentrations. J Anesth 2009, 23:266-269.

18. Martinho A, Goncalves I, Santos CR: Glucocorticoids regulate metallothionein-1/2 expression in rat choroid plexus: effects on apoptosis. Mol Cell Biochem 2013, 376:41-51.

19. Aziz MH, Shen H, Maki CG: Glucocorticoid receptor activation inhibits p53-induced apoptosis of MCF10Amyc cells via induction of protein kinase Cepsilon. J Biol Chem 2012, 287:29825-29836.

20. Forster C, Burek M, Romero IA, Weksler B, Couraud PO, Drenckhahn D: Differential effects of hydrocortisone and TNFalpha on tight junction proteins in an in vitro model of the human blood-brain barrier. J Physiol 2008, 586:1937-1949.

21. Gomes JA, Stevens RD, Lewin JJ 3rd, Mirski MA, Bhardwaj A: Glucocorticoid therapy in neurologic critical care. Crit Care Med 2005, 33:1214-1224.

22. Ma B, Shi J, Jia L, Yuan W, Wu J, Fu Z, Wang Y, Liu N, Guan Z: Overexpression of PUMA correlates with the apoptosis of spinal cord cells in rat neuropathic intermittent claudication model. PLOS One 2013 8:e56580.

23. Laurer HL, Meaney DF, Margulies SS, Mclntosh TK: Modeling brain injury/ trauma. In Encyclopedia of the Human Brain. Edited by Ramachandran VS. San Diego: Academic; 2002:93-102.

24. Jones NC, Cardamone L, Williams JP, Salzberg MR, Myers D, O'Brien TJ: Experimental traumatic brain injury induces a pervasive hyperanxious phenotype in rats. J Neurotrauma 2008, 25:1367-1374.

25. Chen X, Zhang KL, Yang SY, Dong JF, Zhang JN: Glucocorticoids aggravate retrograde memory deficiency associated with traumatic brain injury in rats. J Neurotrauma 2009, 26:253-260.

26. Chen J, Li Y, Wang L, Zhang Z, Lu D, Lu M, Chopp M: Therapeutic benefit of intravenous administration of bone marrow stromal cells after cerebral ischemia in rats. Stroke 2001, 32:1005-1011.

27. Wajanaponsan N, Reade MC, Milbrandt EB: Steroids in late ARDS? Crit Care 2007, 11:310.

28. Ji RR, Schlaepfer TE, Aizenman CD, Epstein CM, Qiu D, Huang JC, Rupp F: Repetitive transcranial magnetic stimulation activates specific regions in rat brain. Proc Natl Acad Sci U S A 1998, 95:15635-15640.

29. van Herck H, Baumans V, Brandt CJ, Hesp AP, Sturkenboom JH, van Lith HA, van Tintelen G, Beynen AC: Orbital sinus blood sampling in rats as performed by different animal technicians: the influence of technique and expertise. Lab Anim 1998, 32:377-386.

30. Donkin JJ, Nimmo AJ, Cernak I, Blumbergs PC, Vink R: Substance P is associated with the development of brain edema and functional deficits after traumatic brain injury. J Cereb Blood Flow Metab 2009, 29:1388-1398

31. Fernandez-Lopez D, Faustino J, Daneman R, Zhou L, Lee SY, Derugin N, Wendland MF, Vexler ZS: Blood-brain barrier permeability is increased after acute adult stroke but not neonatal stroke in the rat. $J$ Neurosci 2012, 32:9588-9600.

32. Gavrieli Y, Sherman Y, Ben-Sasson SA: Identification of programmed cell death in situ via specific labeling of nuclear DNA fragmentation. J Cell Biol 1992, 119:493-501.

33. Lazaridis C, Czosnyka M: Cerebral blood flow, brain tissue oxygen, and metabolic effects of decompressive craniectomy. Neurocrit Care 2012, 16:478-484.

34. Fukuda AM, Pop V, Spagnoli D, Ashwal S, Obenaus A, Badaut J: Delayed increase of astrocytic aquaporin 4 after juvenile traumatic brain injury: possible role in edema resolution? Neuroscience 2012, 222:366-378
35. Wang T, Chou DY, Ding JY, Fredrickson V, Peng C, Schafer S, Guthikonda M, Kreipke C, Rafols JA, Ding Y: Reduction of brain edema and expression of aquaporins with acute ethanol treatment after traumatic brain injury. J Neurosurg 2013, 118:390-396.

36. Asehnoune K, Roquilly A, Sebille V: Corti TCtg: Corticotherapy for traumatic brain-injured patients-the Corti-TC trial: study protocol for a randomized controlled trial. Trials 2011, 12:228.

37. Kwon YS, Suh GY, Jeon K, Park SY, Lim SY, Koh WJ, Chung MP, Kim H, Kwon OJ: Serum cytokines and critical illness-related corticosteroid insufficiency. Intensive Care Med 2010, 36:1845-1851.

38. Annane D, Sebille V, Charpentier C, Bollaert PE, Francois B, Korach JM, Capellier G, Cohen Y, Azoulay E, Troche G, Chaumet-Riffaud P, Bellissant E: Effect of treatment with low doses of hydrocortisone and fludrocortisone on mortality in patients with septic shock. JAMA 2002, 288:862-871.

39. Dimopoulou I, Tsagarakis S, Kouyialis AT, Roussou P, Assithianakis G, Christoforaki M, llias I, Sakas DE, Thalassinos N, Roussos C: Hypothalamicpituitary-adrenal axis dysfunction in critically ill patients with traumatic brain injury: incidence, pathophysiology, and relationship to vasopressor dependence and peripheral interleukin-6 levels. Crit Care Med 2004, 32:404-408.

40. Jaattela M, Ilvesmaki V, Voutilainen R, Stenman UH, Saksela E: Tumor necrosis factor as a potent inhibitor of adrenocorticotropin-induced cortisol production and steroidogenic P450 enzyme gene expression in cultured human fetal adrenal cells. Endocrinology 1991, 128:623-629.

41. Bratton SL, Chestnut RM, Ghajar J, McConnell Hammond FF, Harris OA, Hartl R, Manley GT, Nemecek A, Newell DW, Rosenthal G, Schouten J, Shutter L, Timmons SD, Ullman JS, Videtta W, Wilberger JE, Wright DW: Guidelines for the management of severe traumatic brain injury. XV. Steroids. J Neurotrauma 2007, 24:S91-S95.

42. Roberts I, Yates D, Sandercock P, Farrell B, Wasserberg J, Lomas G, Cottingham R, Svoboda P, Brayley N, Mazairac G, Laloë V, Muñoz-Sánchez A, Arango M, Hartzenberg B, Khamis H, Yutthakasemsunt S, Komolafe E, Olldashi F, Yadav Y, Murillo-Cabezas F, Shakur H, Edwards P: Effect of intravenous corticosteroids on death within 14 days in 10008 adults with clinically significant head injury (MRC CRASH trial): randomised placebo-controlled trial. Lancet 2004, 364:1321-1328.

43. Chen $X$, Lin YP, Wang D, Zhang JN: Dexamethasone exacerbates spatial acquisition deficits after traumatic brain injury in rats. Neurol Res 2010 32:1097-1102

44. Rink A, Fung KM, Trojanowski JQ, Lee VM, Neugebauer E, McIntosh TK: Evidence of apoptotic cell death after experimental traumatic brain injury in the rat. Am J Pathol 1995, 147:1575-1583.

45. Schoknecht $\mathrm{K}$, Shalev $\mathrm{H}$ : Blood-brain barrier dysfunction in brain diseases: clinical experience. Epilepsia 2012, 53:7-13.

46. Gursoy-Ozdemir Y, Yemisci M, Dalkara T: Microvascular protection is essential for successful neuroprotection in stroke. J Neurochem 2012, 123:2-11.

47. Perez-Polo JR, Rea HC, Johnson KM, Parsley MA, Unabia GC, Xu G, Infante SK, Dewitt DS Jr, Hulsebosch CE: Inflammatory consequences in a rodent model of mild traumatic brain injury. J Neurotrauma 2013, 30:727-740.

48. Yang $Y$, Rosenberg GA: Blood-brain barrier breakdown in acute and chronic cerebrovascular disease. Stroke 2011, 42:3323-3328.

49. Ramirez SH, Fan S, Dykstra H, Rom S, Mercer A, Reichenbach NL, Gofman L, Persidsky $Y$ : Inhibition of glycogen synthase kinase 3beta promotes tight junction stability in brain endothelial cells by half-life extension of occludin and claudin-5. PloS One 2013, 8:e55972.

50. Zhao J, Moore AN, Redell JB, Dash PK: Enhancing expression of Nrf2-driven genes protects the blood brain barrier after brain injury. J Neurosci 2007, 27:10240-10248.

51. Schimmer BP, Funder JW: ACTH, Adrenal Steroids, and Pharmacology of the Adrenal Cortex. In Goodman and Gilman's The Pharmacological Basis of Therapeutics. 12th edition. Edited by Brunton LL, Chabner BA, Knollmann BC. New York: McGraw-Hill Medical; 2011:1209-1236.

52. Krugers HJ, Hoogenraad CC, Groc L: Stress hormones and AMPA receptor trafficking in synaptic plasticity and memory. Nat Rev Neurosci 2010, 11:675-681.

53. Chantong B, Kratschmar DV, Nashev LG, Balazs Z, Odermatt A: Mineralocorticoid and glucocorticoid receptors differentially regulate NFkappaB activity and pro-inflammatory cytokine production in murine BV2 microglial cells. J Neuroinflammation 2012, 9:260. 
54. De Kloet ER, Vreugdenhil E, Oitzl MS, Joels M: Brain corticosteroid receptor balance in health and disease. Endocr Rev 1998, 19:269-301.

55. Schlossmacher G, Stevens A, White A: Glucocorticoid receptor-mediated apoptosis: mechanisms of resistance in cancer cells. J Endocrinol 2011, 211:17-25.

56. Oberleithner H, Riethmuller C, Ludwig T, Shahin V, Stock C, Schwab A, Hausberg M, Kusche K, Schillers H: Differential action of steroid hormones on human endothelium. J Cell Sci 2006, 119:1926-1932.

57. Crochemore C, Lu J, Wu Y, Liposits Z, Sousa N, Holsboer F, Almeida OF: Direct targeting of hippocampal neurons for apoptosis by glucocorticoids is reversible by mineralocorticoid receptor activation. Mol Psychiatry 2005, 10:790-798.

doi:10.1186/cc13067

Cite this article as: Chen et al: Stress-dose hydrocortisone reduces critical illness-related corticosteroid insufficiency associated with severe traumatic brain injury in rats. Critical Care 2013 17:R241.

\section{Submit your next manuscript to BioMed Central and take full advantage of:}

- Convenient online submission

- Thorough peer review

- No space constraints or color figure charges

- Immediate publication on acceptance

- Inclusion in PubMed, CAS, Scopus and Google Scholar

- Research which is freely available for redistribution 